\title{
PRESSURE ANALYSIS AND FLUID CONTACT PREDICTION FOR ALPHA RESERVOIR (A PARTIALLY APPRAISED FIELD) ONSHORE NIGER DELTA.
}

\author{
A. Ogbamikhumi $1{ }^{1}{ }^{*}$, A. H. Akenzua-Adamczyk ${ }^{2}$ and L. Ahiwe ${ }^{3}$

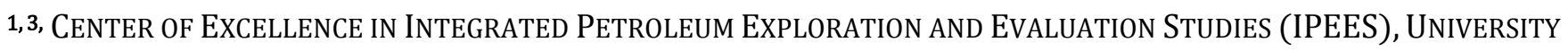 \\ of BENIN, BENIN CITY, Edo STATE. NIGERIA. \\ 2, DePartment of GEology, University of Benin, Benin City, Edo STATE. NIGERIA. \\ E-mail addresses: ${ }^{1}$ alexander.ogbamikhumi@uniben.edu, ${ }^{2}$ aiyevbekpen.akenzua@uniben.edu, ${ }^{3}$ lahiwe@gmail.com
}

\begin{abstract}
The study field is green, with limited well penetrations. The objective reservoir (Alpha Reservoir) is a relatively shallow one, with 6 wells penetration. Two of the wells are wet (Water-Up-To) while the rest penetrated hydrocarbon bearing intervals (Gas-Down-To). As pressure data was not acquired in the water leg of the reservoir, pressure gradient analysis was done with the field-wide hydrostatic profile for contact and fluid prediction. Also, an evaluation of the possibility of having an oil rim within the region of fluid-type uncertainty was carried out. The predicted results revealed that the objective reservoir has the potential of having oil rim of a possible gradient 0.20 psi/ft, with a column height of less than or equal to 20ft. Such an oil column if present is deemed insignificant. Therefore, the reservoir can be developed as a nonassociated gas reservoir with a predicted Gas-Water-Contact of $7529 \mathrm{ftss}$.
\end{abstract}

\section{Keywords: Gas-Down-To, Water-Up-To, Oil Rim Reservoir, Pressure Analysis, Fluid Content}

\section{INTRODUCTION}

Hydrocarbon accumulation in most reservoirs comes in associations. That is, a particular reservoir having accumulations of oil and/or gas with water. Such reservoirs where gas accumulation is in association with a considerable amount of oil is known as oil rim reservoirs, while the gas is known as an associated gas. The development of associated gas or oil rim reservoirs requires careful consideration in order to maximize the economic value of the asset. Early oil rim development can be negatively impacted by water coning and/or early gas breakthrough.[1].0il rim reservoirs are common in some basins including the Niger Delta basin of Nigeria. However, most Niger Delta fields typically comprise of stacked multiple reservoirs, sometimes with more than one culmination in a particular sand unit. Due to the occurrence of numerous hydrocarbon-bearing intervals in these stacked reservoirs, it is often unlikely that an appraisal well down-dip of the structures will provide fluid contacts information at all levels in the field. The presence of an oil rim in a predominantly gas reservoir can go a long way in influencing the long term development philosophy. Hence it is important to determine the associated fluid types present in a reservoir.
The study field predominantly contains gas and several reservoirs have been identified. There have been five other wells drilled into the structure. (MAR-09, MAR-15, MAR-01, MAR-8, MAR-03) There has been no production from this field and as such, designated as a green field. This study will focus on one of the reservoirs identified in the field (Alpha Reservoir).

The Alpha reservoir is relatively shallow (approximately $8000 \mathrm{ft}$ ), and is predominantly gas-bearing. The sparse well penetration in the field has given rise to a lack of proper understanding of the structural complexity as well as property distribution within the field especially, our reservoir of interest. This major field uncertainty is further compounded by the inability to properly characterize reservoir fluid, due to unavailable fluid sample and PVT report. Again, no fluid contact has been logged in the Alpha reservoir from the wells already drilled in the field. Only a Gas-Down-To (GDT) has been established from Mar-01A well at 7431ftss. Also, a Water-Up-To (WUT) has been established from Mar-09 well at $7534 \mathrm{ftss}$. This leaves an uncertain fluid column of $103 \mathrm{ft}$. and creates the possibility of having an oil rim within this depth range (Figure 4). The presence of an oil rim in a predominantly gas reservoir can go a long way in influencing the long term development strategy of the reservoir [1]. 


\subsection{Geology of Study Area}

The study field is a partially appraised field located within the central swamp of the Niger Delta basin. The Niger Delta Basin occupies the Gulf of Guinea continental margin in equatorial West Africa between Latitude $3^{0}$ and $6^{0} \mathrm{~N}$ and Longitude $5^{0}$ and $8^{\circ} \mathrm{E}$. It ranks among the world's most prolific petroleum producing Tertiary Deltas[2].The stratigraphy, Sedimentology, structural configuration and paleo-environment in which the reservoir rocks accumulated have been studied by various workers $[3,4]$.

The Niger Delta is framed on the northwest by a subsurface continuation of the West African Shield, the Benin Flank. The eastern edge of the basin coincides with the Calabar Flank to the south of the Oban Masif [5]. Well sections through the Niger Delta generally display three vertical lithostratigraphic subdivisions: an upper delta top facies; a middle delta front lithofacies; and a lower pro-delta lithofacies [3]. These lithostratigraphic units correspond respectively with the Benin Formation (Oligocene-Recent), Agbada Formation (Eocene-Recent) and Akata Formation (Paleocene-Recent) [4]. Our objective reservoir is one of the multiple stacked reservoir characteristics of the Agbada Formation of the Niger Delta Basin.

\section{METHODOLOGY}

Pressure data were obtained at various reservoir levels within the field. FIT (Formation Interval Tester) data were acquired in MAR-01A while RCI (Reservoir Characterization Instrument) data was acquired in MAR15. Pressure Gradient Analysis was adopted in this study for contact prediction and investigation of a possible oil rim within the objective reservoir. The theory here is based on the variation in fluid gradient especially around the GOC. In testing the possibility of an oil rim in the objective reservoir, where a gas column has been established, the three different possible oil gradients in the Niger Delta Basin were plotted below the gas gradient line, against the established field wide hydrostatic line. Different depth realizations were tested below the established Gas-Down-To (GDT) in order to evaluate the possibility of a GOC/OWC. The idea is that, should an oil rim exist within the interval of investigation, the pressure gradients of oil, will establish a pressure gradient profile such that the oil gradient line will intersect the hydrostatic line above the Water-Up-To (WUT) line to define the OWC if present. The model was also calibrated with data from reservoirs with established contacts in the field.

\section{RESULTS AND DISCUSSION}

In the field, pressure typically increases with depth. The pressure data generally fell on a single gradient within each reservoir level, suggesting good lateral pressure continuity (Figure 1). The field is also normally pressured, with a hydrostatic gradient of $0.4332 \mathrm{psi} / \mathrm{ft}$.

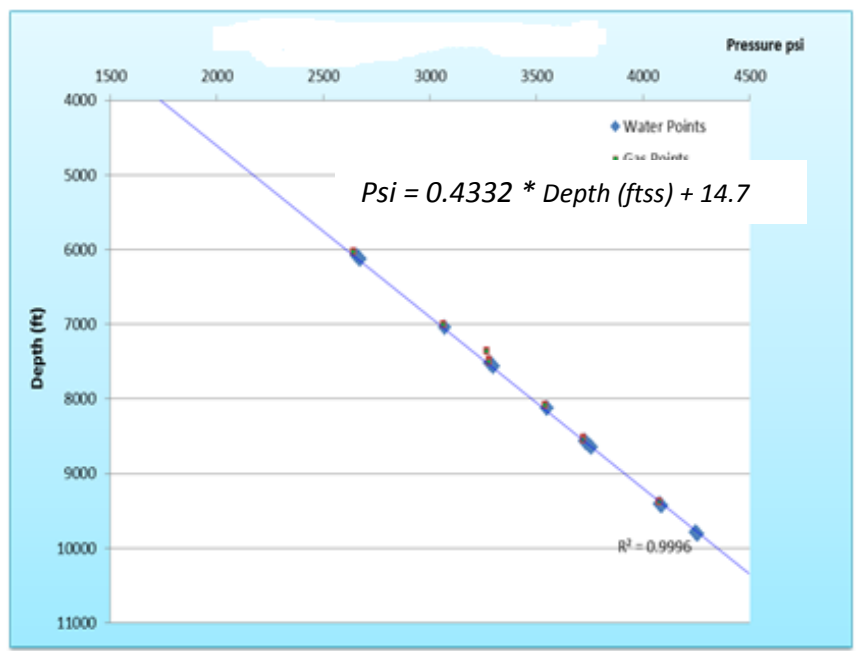

Figure 1: Field-wide pressure profile

The analysis of reservoir pressures data acquired in the Alpha reservoir and the field in general was used to evaluate and reduce the uncertainty around fluid contact. However, before adopting this procedure, the pressure data acquired across the field was plotted and calibrated against well logs (Caliper logs, Gamma ray logs, Resistivity logs, and Neutron Density logs cross plot) at reservoir levels where contacts were logged. For the reservoirs that have pressure points in both the gas and water legs, The analysis result showed good contact alignment with logged data with a $\pm 5 \mathrm{ft}$. difference in depth (Figure3). On reservoir levels with just one or no pressure point acquired in the water leg, the field-wide hydrostatic trend was used as the water gradient line (Figure1). In this case, the result showed reasonable consistency with logged contact with a maximum difference of $\pm 4 \mathrm{ft}$. in depth (figure2).

The pressure-depth plot of the objective reservoir shows an unknown fluid column of $103 \mathrm{ft}$. (figure4). The Column of unknown fluid between the established GDT and the WUT was investigated with a view to finding out the possibility of having an oil rim anywhere below the GDT. If an appreciable oil rim is established, the overall development strategy of the reservoir will be affected. To achieve the aim of the investigation, sensitivities were carried out at various depths below the GDT, with possible oil gradients $(0.2,0.29$ and $0.38 \mathrm{psi} / \mathrm{ft}$.) as found in the Niger Delta region, where the field/reservoir is located. The analysis showed that at depths below the GDT up to about $20 \mathrm{ft}$ above the WUT line, there was no 
intersection of the oil and water lines above the WUT for any of the possible oil gradients (Figure 5, 6 and 7). A maximum possible oil-rim column of about $20 \mathrm{ft}$ above the WUT (assumed to be the GOC, if oil were to be present) was estimated from point of intersection of the $0.2 \mathrm{psi} / \mathrm{ft}$.oil gradient line with the WUT line (Figure 8).
An oil accumulation with such gradients will be very light oil. As a result of this conclusion, the gas gradient line was extended below the Gas-Down-To (GDT) to intercept the hydrostatic line at $7529 \mathrm{ft}$. (Figure 9). This becomes the established Gas-Water-Contact (GWC).

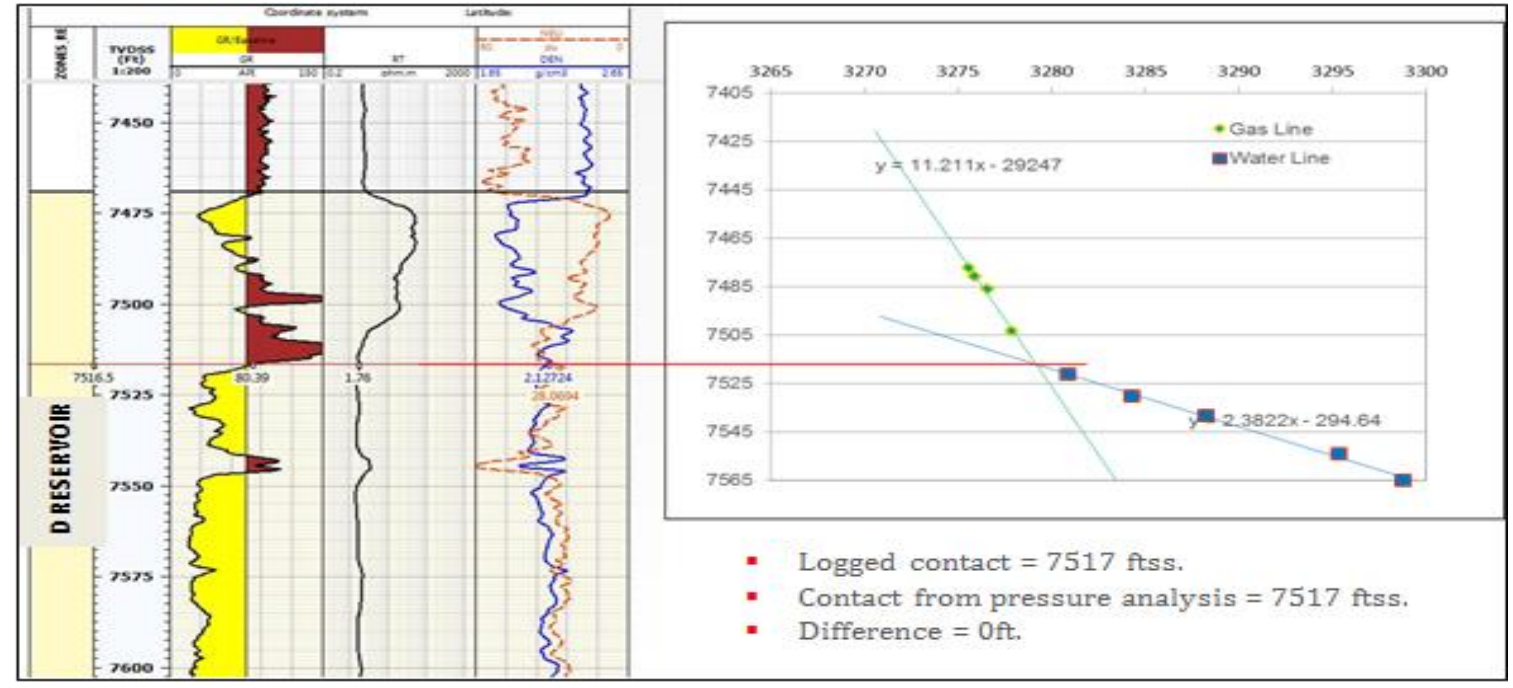

Figure 2: Result of pressure analysis on D-Reservoir

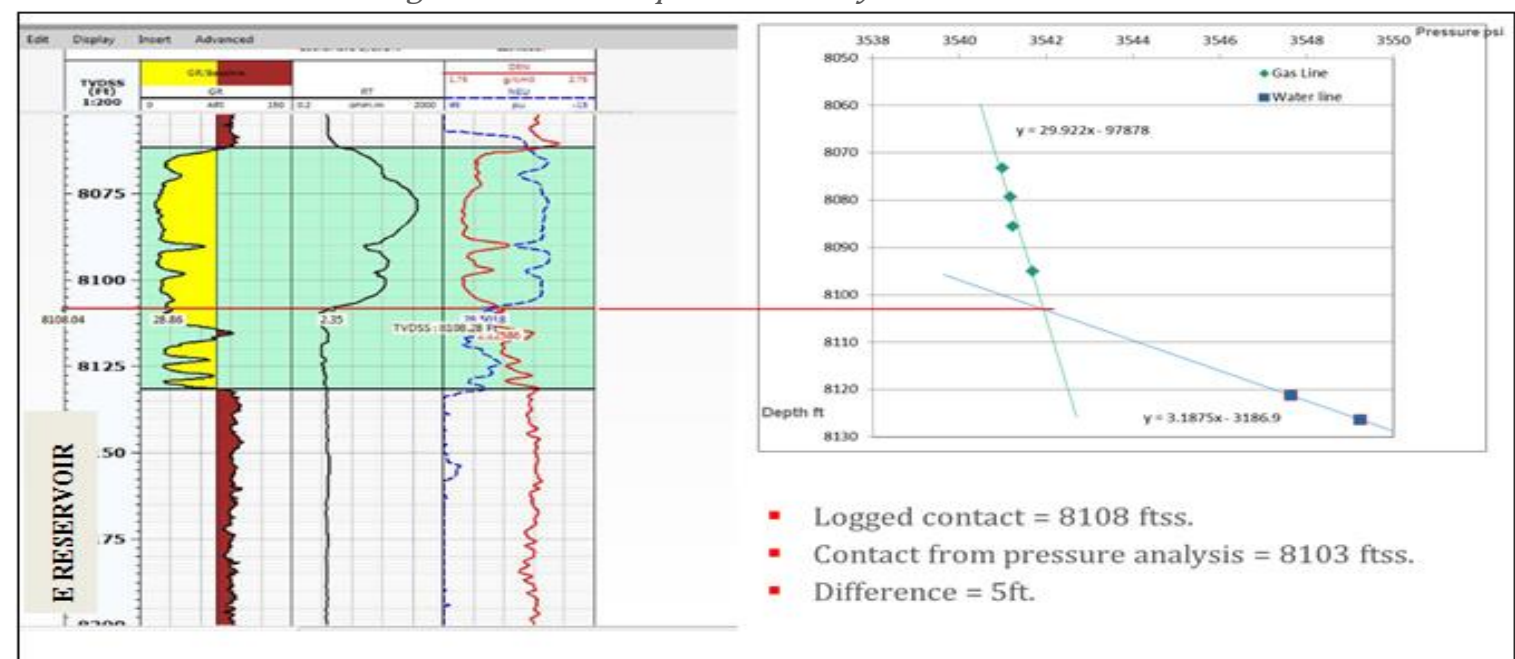

Figure 3: Result of pressure analysis on E-Reservoir

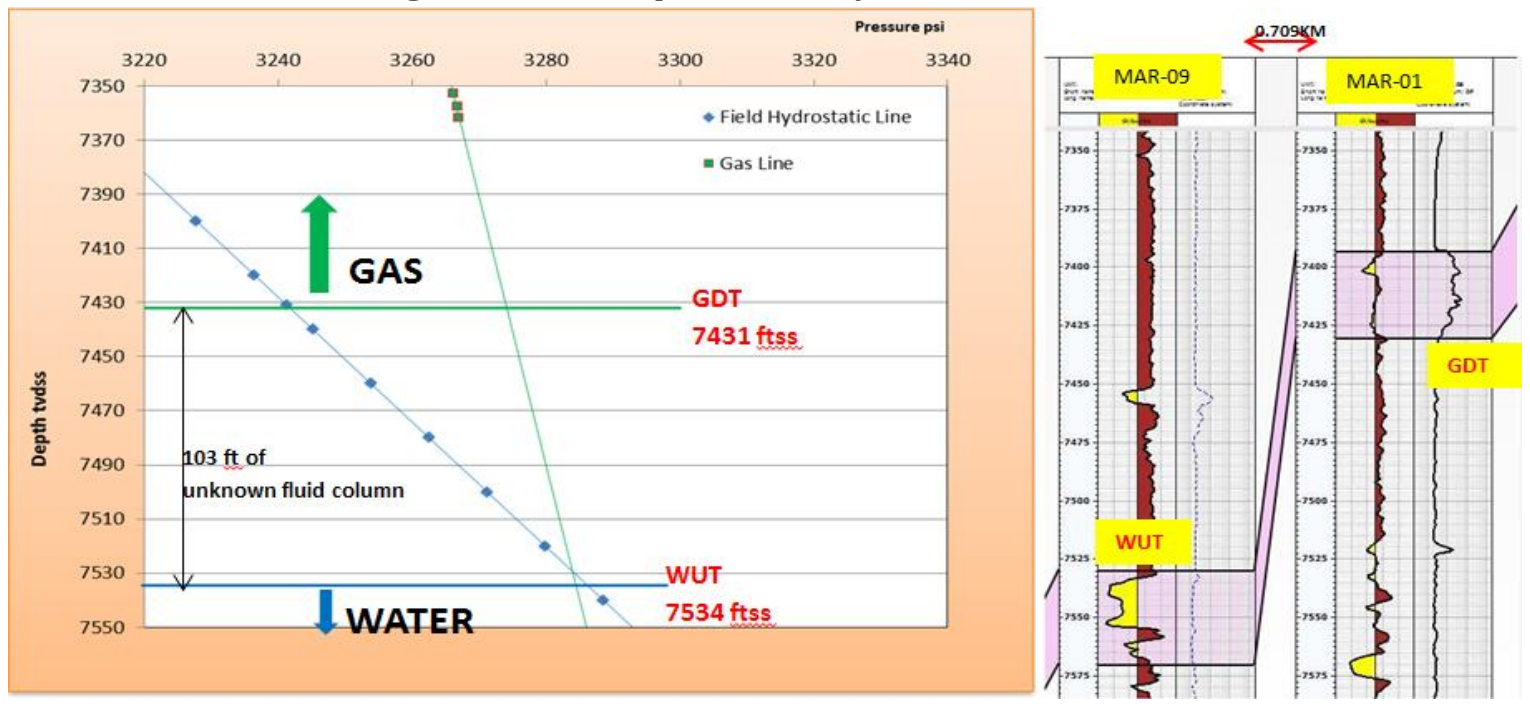

Figure 4: Pressure-Depth Profile and MAR-09 and MAR01 wells of the Alpha Reservoir Showing Unknown Fluid Colum 


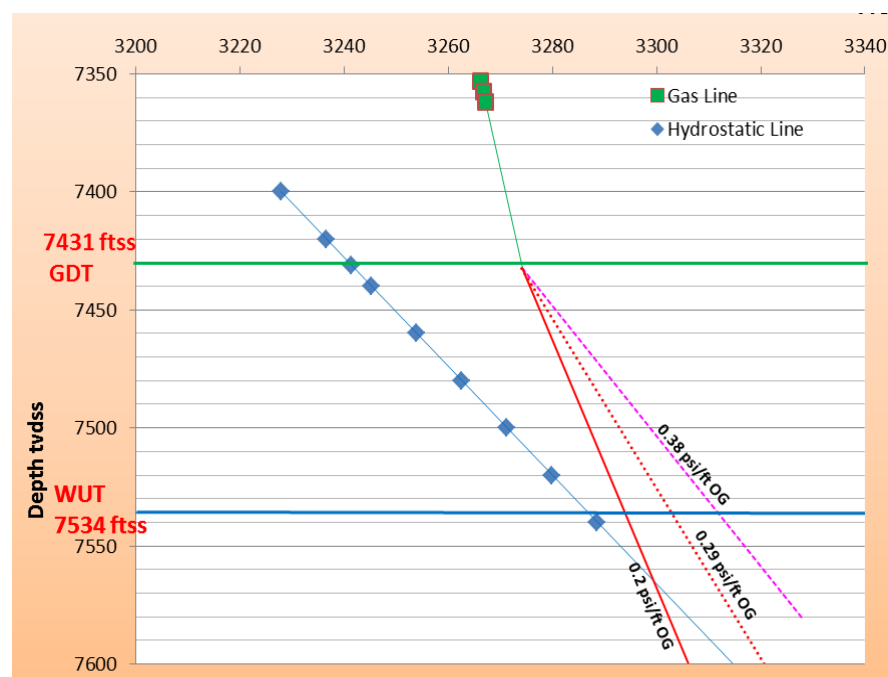

Figure 5: Pressure analysis of Alpha reservoir; Assuming there is oil just below the GDT i.e. GDT $=$ GOC, No intersection of the oil and water lines above the WUT for any of the possible oil gradients $0.2,0.29 \& 0.38$ si/ft. respectively

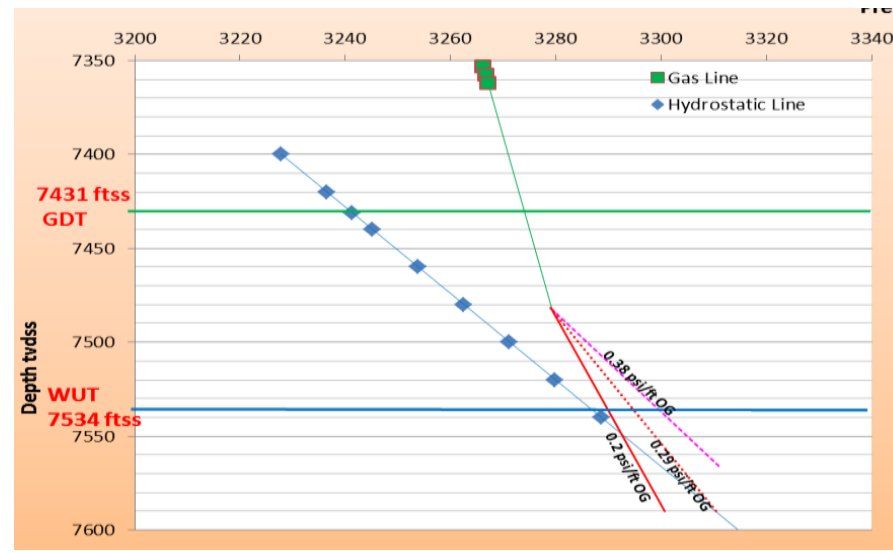

Figure 6: Pressure analysis of Alpha reservoir; Assuming there is oil midway btw GDT \& WUT i.e. GOC $=($ GDT $+W U T) / 2=$ $7482 \mathrm{ft}$. No intersection of the oil and water lines above the WUT for any of the possible oil gradients 0.2, 0.29 and o.38psi/ft.respectively.

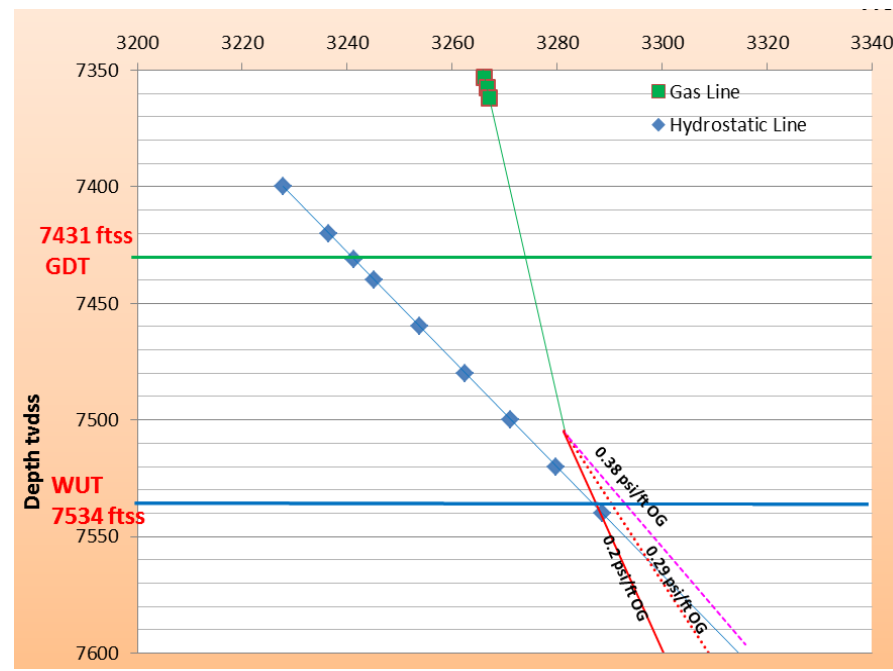

Figure 7: Pressure analysis of Alpha reservoir; Assuming there is oil 30ft above WUT i.e. GOC $=7504 \mathrm{ft}$. No intersection of the oil and water lines above the WUT for any of the possible oil gradients 0.2, 0.29 and 0.38psi/ft. respectively.

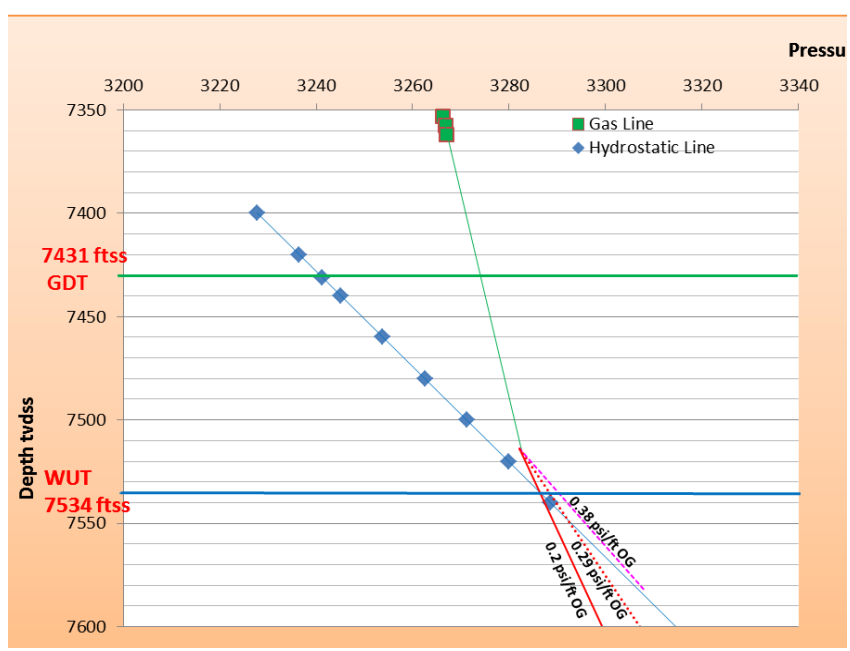

Figure 8: Pressure analysis of Alpha reservoir; Assuming there is oil $20 \mathrm{ft}$ above WUT i.e. GOC $=7514 \mathrm{ft}$. At 20ft above WUT, the $0.2 \mathrm{psi} / \mathrm{ft}$. oil gradient line intersects the water line at the WUT line. This implies that even if there is an oil rim in the reservoir, the maximum oil rim thickness will be about $20 \mathrm{ft}$.

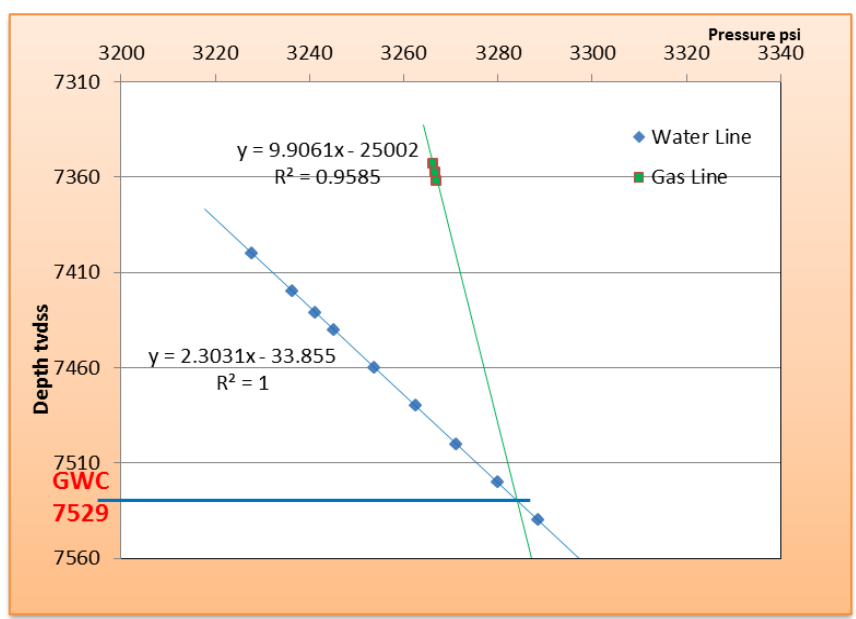

Figure 9: Pressure-Depth Profile of the Alpha Reservoir Showing the GWC

\section{CONCLUSION}

The pressure gradient analysis done for the reservoirs in the field established that the field wide hydrostatic gradient plot can be relied upon for pressure gradient analysis on reservoirs where no pressure data has been acquired at their water leg. The contact prediction for some reservoir in our field of study yielded result that compared reasonably with the logged contact when both the field wide hydrostatic pressure gradient and pressure gradient from acquired data of the water leg from the concern reservoir were used. Therefore, for our objective reservoir with no pressure data collected at the water leg, the field wide hydrostatic gradient profile was also used for the pressure analysis. The assessment of oil rim possibility show that none of the oil gradient line intersected the hydrostatic line above the WUT. It was demonstrated in Figure 7, that only the 0.29Psi/ft. oil gradient line intersect the hydrostatic line at the WUT, 
which assumes that there could be oil at $20 \mathrm{ft}$ above the WUT (i.e. GOC). Therefore, a GWC was estimated at $7529 \mathrm{ft}$. Even if an oil rim was present, it is not expected to have a column thickness above $20 \mathrm{ft}$. Therefore the reservoir can be developed as a non-associated gas reservoir.

\section{REFERENCES}

[1] Onyeukwu, I. H., Peacock, A., Matemilola, A. and Igiehon, 0. "Improving Recovery from Oil Rim Reservoirs by Simultaneous Gas and Water Injection," Nigeria Annual International Conference and Exhibition Lagos, Nigeria: Society of Petroleum Engineering, 2012.
[2] Doust, H. and Omatsola, E. "Niger Delta, Divergent/ Passive Margin Basin" American Association of Petroleum Geologist Memoir, Vol. 48, pp. 207-238, 1990.

[3] Reijers, T. J. A., Petters, S. W., and Nwajide, C. S. "The Niger Delta Basin," Amsterdam Elserview, pp. 150$170,1996$.

[4] Short, K. C., and. Stauble, A. J. "Outline of the Geology of Niger Delta," American Association of Petroleum Geologist Bulletin, Vol. 51, pp. 761-779, 1967.

[5] Murat, R. C. Stratigraphy and Paleo-Geography of the Cretaceous and Lower Tertiary in Southern Nigeria: Ibadan University Press, 1972. 